\title{
Measuring the Income Inequality in Nigeria: the Lorenz Curve and Gini Co-efficient Approach
}

\author{
Bakare A. S.
}

Department of Economics, Adekunle Ajasin University, P.M.B 001 Akungba- Akoko, Ondo State, Nigeria

\begin{abstract}
In recent years, especially since the mid 1990s, there have been debates and commentaries exploring the concept, types, sizes and economic implications of income inequalities. This study carried out a quantitative measure of the size and the core determinant of income inequality in Nigeria. The study used standard traditional measurement approach: the Lorenz Curve and Gini Co-efficient to determine the size of income inequality and ordinary least square simple regression method to analyze the basic determinant of income inequality in Nigeria. The Gini co-efficient of Nigeria lies between 46 and 60 percent. From the result obtained, we discovered that there is a disturbing income inequality in Nigeria. The regression result shows that 1 percent increase in the literacy rate increase the Gini coefficient by 3 percent meaning that there is higher disparity in the income distribution in Nigeria with increase in literacy rate. The findings of the study support the need for the government to formulate policies targeting at improving the welfare of the poor and those that provide employment and improve the lot of low-paid workers.
\end{abstract}

Keywords Income Inequality, Lorenz Curve, Gini Co-Efficient

\section{Introduction}

Variation in income is highly visible in most part of the economies of the Third World nations especially Nigeria. The income and the wealth of the country seem to be unevenly distributed. We have some set of people who are very rich whose living standards are relatively high. Such people have access to the basic needs of life such as balance diet, convenient shelter, basic infrastructure, good clothing e.t.c. At the same time we have some other set of people that are very poor who are struggling to survive with less than the U.S $\$ 370$ a year or a dollar a day. Such people are characterized by Poor health, illiteracy, poverty, unstably job, lack of basic needs such as food, clothing and decent shelter. The extent and magnitude of the disparity is visible but not defined in quantitative terms. The gap between the rich and the poor appears wide, yet they are not vividly derived.

Income inequality may be considered in relation to a number of interrelated factors such as education, occupation, regional, ethnical, rural expenditure pattern and even political differences. These factors dot not only produce a similar pattern of income distribution but also create a context of community infrastructure through policies that affect education, public health and services, transportation, occupational health regulations, availability of health food.

* Corresponding author:

stevebakare@yahoo.com (Bakare A. S.)

Published online at http://journal.sapub.org/economics

Copyright (C) 2012 Scientific \& Academic Publishing. All Rights Reserved
Among these factors, education appears to play a major role. It has been established that educational factors-higher attainment and more equal distribution of education play a significant role in making income distribution to be more equal (Gregorio and Lee, 1999). Apart from the direct benefit itself, education is a means of acquiring special skills and raising the level of productivity of the individual. The more years spent in acquiring education, the more skills and the higher return will accrue. Aboyade (1973) had found that the average earnings of workers with complete primary education were about 1.7 times that of illiterates. Workers with secondary education had average earning of about 1.6 times the level of primary school graduate and about 2.7 times that of illiterates, while university graduates had average earnings about 12 times the level of illiterates and about 4.5 time the level of secondary school graduate. In a similar study Diejomaoh and Anusionwu (1981) concluded that the income disparity between primary and secondary school graduate was about 50 percent while the disparity between primary and secondary school graduates was about 60 percent

Apart from the general education, some other type of profession and occupation also has some influence on income distribution. A medical doctor will earn more than a graduate of Economics. A medical doctor in the army will more than one in the civil service, and a senior medical officer will earn more than a newly recruited one. In the Nigerian university system, a graduate entering the academic profession is place two steps ahead his counterparts in the non academic cadre. In general, it has also been observed 
that workers in the petroleum sector are the highest paid workers in Nigeria. They are followed by those in the communication and banking sector in that order.

Disparity in income distribution is also noted to have been drawn along rural/urban setting. Ladipo and Adesimi (1981) had found out that a continuing existence of disparity in income between rural and urban centres in Nigeria. The low income earned by the rural dwellers is readily attributable to the fact that majority of them are primary producers whereas as the urban dwellers are made up mainly of salary/wage earners, working in either private or public organizations, or business men/contractors. Urban centres are recognized to be made up people with relatively more buoyant economies and steadily rising incomes and employment opportunities while the rural dwellers depend more on relatively stagnant agricultural economies. In consonance with our earlier discussion, income disparity was also noticed among different occupational groups in the rural areas.

In a more recent study concerning elderly people in rural and urban China, Neveda Da Costa and Ji (2004) found a significant difference in rural versus urban income inequality. They attributed this to a number of factors among which are: (i) elderly people in the urban areas are more educated and therefore have opportunity to be employed either fully or partially after retirement, (ii) they are more connected with government officials and therefore benefit more from government support programmes and (iii) they are entitle to earn pension.

Turning to the measurement of income distribution, there are basically two approaches; functional and size distribution. While the former refers to divisions among the traditional factors of production land, labour and capital and the entrepreneur, the latter refers to the distribution of income on the basis of levels of family income. Discussions in microeconomic theory usually focus on ownership pattern of production factors as the main determinants of income distribution. According to this line of thought, if land and capital are in the hands of a few members of the society higher return to these factors will tend to worsen the welfare situation. A more even distribution will be achieved if there are higher returns to the more widely distributed unskilled labour.

In more concrete terms, income distribution is measured in terms of size. In these cases, a sample survey of households' annual income is undertaken and individual or households are ranked by income. Using the mid-point of each size class the cumulative percentage distribution is measured and income equality measured by how much income is earned by different segment of population. For instance if all workers are broken into five segmenting terms of how much they earn, the questions will then be asked about what percentage of all income goes the lowest 20 percent of the population, what goes to the lowest 40 percent, the lowest 60 percent and so forth.

If every one earns exactly the same amount, then the income distribution is perfectly equal. If no one earns money except for one person, who earns all the money, then income distribution is perfectly unequal. Usually, however a societies income distribution falls somewhere between the two extremes.

\section{The Problem and the Objectives of the Study}

In recent years, especially since the mid 1990s, there have been debates and commentaries exploring the concept, types, sizes and economic implications of income inequalities. These studies discussed the income inequality hypothetically. For instance, Todaro in his popular book on development used hypothetical figure to explain the gaps between the rich and the poor using Lorenz curve and Gini-coefficient. His usual case study did not apply the data of any specific country. Some other authors have their studies focused on the question of growth versus income distribution. They argue that development required a higher GNP and a faster growth rate. The basic issue, which is poverty and inequality, continue to worsen despite the emphasis placed on the economic growth. Thus many Third World countries especially Nigeria that had experienced relatively high rates of economic growth by historical standards began to realize that such growth had brought little in the way of significant benefits to their poor. For those millions of people in Nigeria, the levels of living seemed to be declining in real terms. The rise in the rates of rural and urban unemployment and underemployment is worrisome. The distribution of incomes which becomes less equitable with each passing year is all the more worrisome. It is now obvious that rapid economic growth had failed to eliminate or even reduce widespread absolute poverty.

In compliment of the foregoing, Nigeria's Vision 2010 asserted that "despite decades of development efforts, both the gap between the rich and poor manifested in income inequalities and widespread poverty within the country have continue to widen and remains the major challenge to the development efforts of the country". This view was echoed again and again in Vision 2020. In order to determine the dimensions of the problem, it is however important and instructive to investigate the extent and magnitude of the income inequality in Nigeria. This constitutes our basic problem-solving approach. First, we define the nature of the income distribution problem and measure its quantitative significance in Nigeria. We then set forth an empirical machinery to determine the relationship between income inequality and poverty and summarily explore alternative possible policy approaches directed at the elimination of poverty and the reduction of excessively wide disparities in Nigeria's distribution of income. A thorough treatment of these two fundamental cases forms the objective of this study. The rest of this paper is organized as follows: Section 2 presents the literature review and the theoretical framework. The methodology of the study is discussed in section 3 . In section 4 we carry out the measurement of the income inequality using the Lorenz curve and the Gini-coefficient while in section 5 we carry out the empirical study of the relationship between income inequality and poverty. Section 6 summarizes the 
findings, draws conclusions and makes policy recommendations.

\section{Literature Review}

The literature is scanty on the concepts, incidence, sizes and measurement of income inequality. From the standpoint of concept, income distribution connotes a situation whereby money received during a certain period, especially as payment for work or interest on investment are in different sizes, degrees or circumstances etc, especially in an unfair difference in ranking. In the same vein, the advance learner's dictionary gave us a layman's perspective of income inequality to mean differences in the amount which one receives regularly for daily spending. Graham (1995) regarded income inequality as line drawn between the rich and the poor. As higher income is found within the majority of the urban dwellers, low income is found within the majority of the rural households except for the few in the rural areas who own productive assets and are engaged in some commercial ventures. According to Sando (1996), the low income group is characterized by poverty, poor health, unstable job, inadequate level of education (illiteracy) while the high income group is characterized by adequate health care, literacy (adequate education attained). The middle group shares those characteristics between the low and the higher income group. The survey carried out by the World Bank (1996) made us to realize that the poor are often illiterates and often in poor health and have a stunted life span. In corroborating this argument, Olayemi (1995) opined that lack of access to basic needs and necessities of life such as goods, clothing and decent shelter, inability to meet social and economic obligation in Nigeria, lack of skills and gainful employment characterize income inequality. Kuh et al, (1997) found education as the key mediator in this reasoning. Family circumstances which influences one in the childhood is a central determinant of income inequality in the adulthood Kuh et al, (1997) concluded. It is from here we can infer that cultural, political and economic factors create income inequality in the society is usually measured by the use of Lorenz curve. This curve reveals the percentage of society's income that is earned by a given proportion of household in the society. At any point on the curve, a given percentage of societies household receive just the corresponding percentage of society's income. (Iyoha 1998). Deaton (2001) suggests that there are very substantial issues related to both the conceptualization and the measurement of income inequality that are often overlooked. Judge et al., (1998) suggests that the treatment of these issues in the public literature has often been neglected.

\section{Theoretical Framework}

The objective of this study can be explained within the framework of Lorenz curve and Gini coefficient. These theories capture the main feature of the research which is measuring the extent of income inequality in Nigeria.

Lorenz curve is an instrument to analyze personal income statistics. In constructing a Lorenz curve, the numbers of income recipients are plotted on the horizontal axis, not in absolute terms but in cumulative percentages. The vertical axis shows the share of total income received by each percentage of population. It also is cumulative up to $100 \%$, meaning that both axes are equally long. The entire figure is enclosed in a square and a diagonal line is drawn from the lower left corner (the origin) of the square to the upper right corner. At every point on that diagonal, the percentage of income received is exactly equal to the percentage of income recipients - for example, the point halfway along the length of the diagonal represents $50 \%$ of the income being distributed to exactly $50 \%$ of the population. At the three-quarter point on the diagonal, $75 \%$ of the income would be distributed to $75 \%$ of the population. In other words, the diagonal line is representative of "perfect equality" in size distribution of income. Each percentage group of income recipients is receiving that same percentage of the total income; for example, the bottom $40 \%$ receives $40 \%$ of the income, while the top $5 \%$ receives only $5 \%$ of the total income.

The Lorenz curve shows the actual quantitative relationship between the percentage of income recipients and the percentage of the total income they did in fact receive during, say, a given year. The more the Lorenz curve line is away from the diagonal (perfect equality), the greater the degree of inequality represented. The extreme case of perfect inequality (i.e. a situation in which one person receives all of the national income while everybody else receives nothing) would be represented by the congruence of the Lorenz curve with the bottom horizontal and right-hand vertical axes. Because no country exhibits either perfect equality or perfect inequality in its distribution of income, the Lorenz curves for different countries will lie somewhere to the right of the diagonal.

\section{Gini -Coefficients and Aggregate Measures of Inequality}

A final and very convenient shorthand summary measure of the relative degree of income inequality in a country can be obtained by calculating the ratio of the area between the diagonal and the Lorenz curve divided by the total area of the half-square in which the curve lies. (i.e. Gini- coefficient $=\mathrm{A}$ $/ \mathrm{A}+\mathrm{B})$. This ratio is known as the Gini concentration ratio or more simply as the Gini- coefficient, named after the Italian statistician who first formulated in 1912.

Gini- coefficient are aggregate inequality measure and can vary anywhere from 0 (perfect equality) to 1 (perfect inequality). If income is totally equally distributed so that the Lorenz curve follows the 450 line, the Gini- coefficient is zero. As inequality increases, so does area A, the Gini- coefficient rises. In the extreme case of total inequality where one person earns the whole national income, area B would disappear and the Gini-Coefficient would be 1. In actual fact, as we shall soon discover, the Gini- Coefficient for countries with highly unequal income distributions like Nigeria typically lies between 0.50 and 0.70 , while for countries with relatively equitable distributions, it is on the order of 0.20 to 0.35 . 


\section{Methodology and Materials}

\section{Research Design and Strategy}

Research design is the structure and strategy for investigating the relationship between the variables of the study. The research design adopted for this work is the descriptive and experimental research design. The descriptive design enables us to use graph, charts and diagrams to describe the data. In this study we use Lorenz curve and Gini-coefficient to explain the extent of income disparity in Nigeria. The experimental research design is appropriate because it combines the theoretical consideration with empirical observation. It enables a researcher therefore to observe the effects of explanatory variables on the dependent variables.

\section{Population of the Study}

The study will cover Nigeria data from the years 1990 to 2000 which is a period of ten (10) years. This period is appropriate because it captures the transition period during which the government review the salary and wages of the civil servants in Nigeria. It combines the old and new wages and salaries from which we can draw the base periods for data analysis.

\section{Source of Data}

This research relies on data from the secondary sources. Data are gathered from the federal office of statistics (FOS) publication such as, Economic and social Bulletin. Other sources of data are publications from national center for economic management and administration (NCEMA), Nigeria journal of Economic and statistics etc

\section{The Model}

To determine the model for a relationship between income inequality and literacy rate we first state the functional relationship of the two variables

$$
\mathrm{GINI}=\mathrm{f}(\mathrm{LIT})
$$

Where Gini denotes the size of income inequality in Nigeria and LIT the literacy rate. The equation suggests that the size of income inequality in Nigeria depends on the level of literacy.

Equation 1 could be expressed in a linear form as

$$
\text { GINI }=\alpha_{0+} \alpha_{1} \text { LIT }
$$

Econometrically, to include random term, the model is expressed as:

$$
\text { GINI }=\alpha_{0+} \alpha_{1} \operatorname{LIT}+u_{i}
$$

This model implies that the size of income inequality in Nigerian will negatively or positively be related to literacy rate,

\section{A Priori Expectation/Theoretical Analysis of the Model}

From the model, the a priori expectation may be mathematically denoted by: $\alpha_{1}<0$. In line with income inequality model, literacy rate to a large extent; theoretically determine the level of income inequality. Thus literacy rate is expected to have an inverse relationship with the level of poverty. Thus we expect the coefficient of literacy rate to be negative i.e. $\alpha_{1}<0$. The higher the literacy rate, the more equitable the distribution of income in Nigeria. In order words, the higher the literacy rate, the lower the Gini-coefficient the lesser the income inequality. It has a been established that educational factors-higher attainment and more equal distribution of education play a significant role in making income distribution to be more equal (Gregorio and Lee, 1999) Apart from the direct benefit itself, education is a means of acquiring special skills and raising the level of productivity of the individual. The more years spent in acquiring education, the more skills and the higher return will accrue. Aboyade (1973) found that the average earnings of workers with complete primary education were about 1.7 times that of illiterates. Workers with secondary education had average earning of about 1.6 times the level of primary school graduate and about 2.7 times that of illiterates, while university graduates had average earnings about 12 times the level of illiterates and about 4.5 time the level of secondary school graduate. In a similar study Diejomaoh and Anusionwu (1981) concluded that the income disparity between primary and secondary school graduate was about 50 percent while the disparity between primary and secondary school graduates was about 60 percent

Apart from the general education, the type of profession and occupation also has some influence on income distribution. A medical doctor will earn more than a graduate of Economics. A medical doctor in the army will earn more than one in the civil service, and a senior medical officer will earn more than a newly recruited one. In the Nigerian university system, a graduate entering the academic profession is placed two steps ahead his counterparts in the non academic cadre. In general, it has also been observed that workers in the petroleum sector are the highest paid workers in Nigeria. They are followed by those in the communication and banking sector in that order.

\section{Data Processing}

Data collected in this study shall be verified through the use of Lorenz curve and Gini coefficient. The two approaches will be instrumental in determining the existence and the degree of income inequality in Nigeria. The simple least square regression analysis will be used to measure the major determinant of income inequality in Nigeria. Gini-coefficient, which will serve as proxy for income inequality will be regressed against social indicators such as literacy rate. The result will help to demonstrate the relationship between the dependent variable Gini- coefficient [Y] and explanatory variable literacy rate (LIT).

\section{Data Analysis and Interpretation of Results}

This section is basically on the presentations, analysis and discussions of the data collected for the study. Data were collected for the period of 10 years (i.e. 1990-2000). The choice of this period is base on the transition to the civil rule during which salary and wages were adjusted. Thus we regard this period as the base years for the evaluation of the of Lorenz curve for Nigeria. The first part of the section establishes the existence of income inequality in Nigeria. The last part shows the regression analysis of the determinants of income inequality in Nigeria. 
Table 1. The Distribution of Personal Income Affect Direct Tax (1990 - 2000)

\begin{tabular}{|c|c|c|c|c|c|c|c|c|c|c|c|}
\hline $\begin{array}{c}\text { Income Recipients } \\
\text { Quartiles (\%) }\end{array}$ & $\begin{array}{c}\text { \% share } \\
\text { in 1990 }\end{array}$ & $\begin{array}{c}\text { \% share } \\
\text { in 1991 }\end{array}$ & $\begin{array}{c}\text { \% share } \\
\text { in 1992 }\end{array}$ & $\begin{array}{c}\text { \% share } \\
\text { in 1993 }\end{array}$ & $\begin{array}{c}\text { \% share } \\
\text { in 1994 }\end{array}$ & $\begin{array}{c}\text { \% share } \\
\text { in 1995 }\end{array}$ & $\begin{array}{c}\text { \% share } \\
\text { in 1996 }\end{array}$ & $\begin{array}{c}\text { \% share } \\
\text { in 1997 }\end{array}$ & $\begin{array}{c}\text { \% share in } \\
1998\end{array}$ & $\begin{array}{c}\text { \% share } \\
\text { in 1999 }\end{array}$ & $\begin{array}{c}\% \text { share } \\
\text { in 2000 }\end{array}$ \\
\hline $\begin{array}{c}\text { Lowest 20\% } \\
\text { Next 20\% }\end{array}$ & 4.5 & 3.5 & 2.5 & 2.6 & 3.5 & 2.5 & 3.5 & 2.1 & 1.8 & 2.0 & 1.57 \\
\hline $\begin{array}{c}\text { Middle 20\% } \\
\text { Next 20\% }\end{array}$ & 11.1 & 10.0 & 10.3 & 9.0 & 0.8 & 10.1 & 8.1 & 7.1 & 8.0 & 8.0 & 7.5 \\
\hline Highest 20\% & 14.1 & 12.0 & 16.5 & 15.1 & 16.1 & 14.5 & 15.2 & 14.1 & 15.7 & 12.5 & 14.1 \\
\hline & 20.5 & 25.0 & 22.1 & 23.5 & 22.5 & 23.0 & 22.5 & 22.3 & 22.5 & 22.0 & 20.1 \\
\hline & 49.8 & 50.0 & 48.6 & 49.8 & 49.9 & 49.9 & 50.7 & 54.4 & 52.0 & 54.2 & 56.8 \\
\hline & 100.0 & 100.0 & 100.0 & 100.0 & 100.0 & 100.0 & 100.0 & 100.0 & 100.0 & 100.0 & 100.0 \\
\hline
\end{tabular}

Source: Federal Office of Statistics, Lagos

\section{Distribution of Income in Nigeria}

The table below shows the distribution of income groups from 1990 to 2000 . The table reveals the pattern of income distribution that allows the concentration of national income in the hands of the few. It also reveals that everyday, the rich are getting richer while the poor are getting poorer in Nigeria. This is shown on the table below:

Note: Lowest 20\%: street hawkers, traders, farmers, junior administrative workers Next 20\%: Civil servants from G.L 10 to 15 , small scale business owners Middle 20\%: Civil servants from G.L 15, lecturers, military officers Next $20 \%$ : Contractors, Law makers, foreign diplomats, oil company workers Highest 20\%: Foreign investors, top political office holders, past political holders. As shown on the table, within the period of 1990 to 2000 , the share of the lowest group from the GDP never exceeds 5\%.

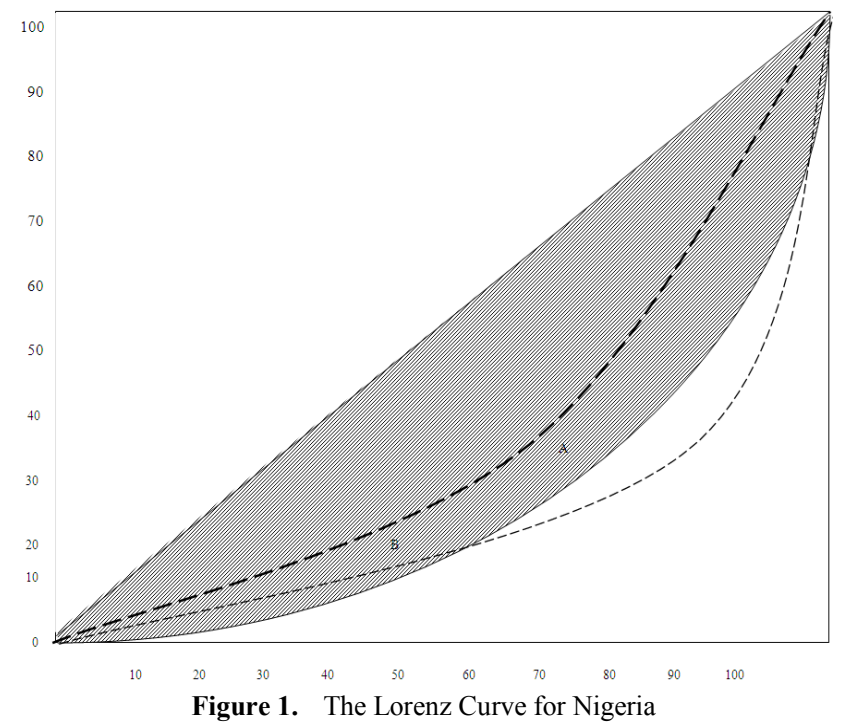

The lion's share of the GDP always goes to the (highest $20 \%$ ) which received $56.8 \%$ of the GDP in 2000 . The pattern of income distribution is such that allows the lowest $20 \%$ and the next $20 \%$ groups to be worse off. The Lorenz Curve of the above data is shown below:

\section{Gini -Coefficient}

Attempt was made to calculate the Gini- coefficient for the Lorenz curves obtained in the preceding section. The results are shown below:

Each big square on the graph has an area of $25 \mathrm{~cm}^{2}$ while the small square has an area of $1 \mathrm{~cm}^{2}$.

$$
\text { Gini }=\frac{\underline{A}}{A+B}
$$

Where $\mathrm{A}=$ shaded portion on the graph, i.e. between line of equality and Lorenz curve B is area below the curve; A + $B=1250$. The estimate for each year is shown on the table below:

Table 2. The Gini-Coefficient for Nigeria for Years 1991-2000

\begin{tabular}{|c|c|c|}
\hline Years & Workings & Gini Coefficient \\
\hline 1991 & $600 / 1250$ & 0.48 \\
\hline 1992 & $625 / 1250$ & 0.50 \\
\hline 1993 & $632 / 1250$ & 0.51 \\
\hline 1994 & $640 / 1250$ & 0.51 \\
\hline 1995 & $641 / 1250$ & 0.51 \\
\hline 1996 & $650 / 1250$ & 0.52 \\
\hline 1997 & $673 / 1250$ & 0.53 \\
\hline 1998 & $672 / 1250$ & 0.53 \\
\hline 1999 & $683 / 1250$ & 0.55 \\
\hline 2000 & $699 / 1250$ & 0.60 \\
\hline
\end{tabular}

Source: Author's Computation

\section{Discussions}

The convenient shorthand summary measure or index of the relative degrees of income inequality is Gini-coefficient. This is calculated as the ratio of the area between diagonal and the larger curve (i.e. the total arc) in which the curve lies. Its value varies between 0 which perfect equality and one (1) which is perfect inequality. A country with highly unequal income distribution has a Gini -coefficient that lies between 0.5 and 0.70 while for a country with relatively equitable distribution of income has Gini -coefficient that lies between 0.20 and 0.35 . Table 2 shows the Gini -coefficient estimates for Nigeria for years 1991 through 2000. From the results, the Gini -coefficient was 0.48 or 48 percent in 1991 and this is the lowest during the periods under evaluation. It averaged 51.0 percent between 1992 and 1995. In the remaining years, the coefficients were greater than half lying between 52.0 and 60.0 percent. The Gini co-efficient has the highest figure of 60.0 percent in 2000 . The estimate reveals that income inequality is very high in Nigeria. A country is considered to have unequal income distribution when its Gini -coefficient is above 35.0 and lies between 20 and 70 percent. The Ginicoefficient of Nigeria lies between 46 and 60 percent. From the result obtained, we discover that there is a disturbing income inequality in Nigeria. All in all, the results obtained buttress the fact that there is income inequality in Nigeria. It indicates that the concentration of income in the hands of the 
few rich. The nation's assets are in the hands of the top 20 percent of the population. The remaining 80 percent wallow in abject poverty.

\section{Regression Results and Discussions}

The time series data obtained from Central Bank bulletin were fitted into the least square income inequality model through simple regression analysis; the parameter estimates were obtained as follows:

$\mathrm{Y}=0.689+0.03666$ LIT

$\mathrm{S} . \mathrm{E}=(0.044)(0.001)$

$\mathrm{t}-$ Value $=(15.582)(3.769)$

$\mathrm{R}^{2}=0.640$

Adjusted $\mathrm{R}^{2}=0.595$

$\mathrm{F}$-statistics $=14.202$

Standard Error of Estimates $=0.02084$

Sum of square of Regression $=0.006$

Sum of square of Residual $=0.003$

\section{Discussions}

The results of the regression are as stated above. The figures in the parentheses are the standard errors and t-statistics respectively. From the above result, the coefficient of the independent variable which is literacy rate is 0.03666 . The positive sign of the parameter shows that there is a direct relationship between income inequality and literacy rate in Nigeria. The regression result shows that 1 percent increase in the literacy rate increase the Gini- coefficient by 3 percent meaning that there is higher disparity in the income distribution in Nigeria with increase in literacy rate. Thus, the null hypothesis which states that literacy in Nigeria does not determine the income inequality is invalidated. Thus will reject the null hypothesis and accept the alternative hypothesis which states that there is a significant relationship between literacy rate and income inequality in Nigeria.

\section{Summary, Conclusion and Recommendations}

The study was focused on the measurement of the existence and magnitude of income inequality in Nigeria and also on tracing the remote causes of such inequality. The study employed theoretical measurement approach and simple regression for the data analysis.

Some of the findings made in the study are as follows:

1. There is income inequality in Nigeria which allows the rich to be getting richer and the poor getting poorer on daily basis.

2. The Lorenz curve and the values of the Gini-coefficient reveal the compositional peculiarities of income distribution in Nigeria. They classified Nigeria as a country with highly unequal income distribution that has a Gini coefficient that lies between 0.46 and 0.60 .

3. The illiteracy rate in Nigeria shows high disparity in the income level of Nigeria. A few rich could afford good education, while the majority could not afford quality education because of low income. Therefore, illiteracy rate becomes both causative and resultant effect of income inequality in Nigeria.

4. The redistribution of income might be a source of poverty since income in the hands of the minority will lead to increase in illiteracy.

It can be concluded that the income inequality of Nigeria is not desirable feature of developing economy. Any country where the distribution of income is heavily concentrated in the hands of the few is an epitome of underdevelopment and poor economic management.

The findings of the study support the need for the government to formulate policies targeting at improving the welfare of the poor and those that provide employment and improve the lot of low-paid workers.

\section{REFERENCES}

[1] Anyawu, J. (1997), "Poverty in Nigeria concept and measurement and determinants" proceedings of the 1997 Annual Conference of the Nigeria Economic Society.

[2] Alkinson A. B (1992), "Measuring poverty and different in family consumption", Economica.

[3] Benzeual and WEBB (2001), Income Inequality and Social Behaviours, London.

[4] Barguyon F. and Marrison, (1998): "Inequality and Development"

[5] Colander C. D. (1994) Economic Richard O. Irwin Inc USA.

[6] Danigar K. and Squire L (1996), “A New Data Set Measuring Income Inequality”, World Bank Economic Review 10

[7] Edozien E. C. (1991): "Inequality and Poverty issue in Concept and thorny" The Nigeria Economic Society.

[8] Graham, (1995): Poverty and Health Risks: Issues and Concept.

[9] Grardtharn U. G. and Johannesson M (2001): "Absolute income inequality and Mortality."

[10] Hardwick, P. et Al. (1994), An Introduction to Modern Economics United State of American

[11] Jain S. B. (1975), "Size Distribution of Income a Computation of Data." The World Bank, Washington.

[12] Judge K, Mulligan J. A. and Benzeval M. (1998) "Income inequality, population and health" Social Science, vol.46 